\title{
Interleukin 16 expression and phenotype of interleukin 16 producing cells in Crohn's disease
}

P Middel, K Reich, F Polzien, V Blaschke, B Hemmerlein, J Herms, M Korabiowska, H-J Radzun

\begin{abstract}
Background-The mechanisms involved in the initiation and maintenance of Crohn's disease are poorly understood. Previous studies have demonstrated an increased number of infiltrating CD4+ T cells within the inflammatory affected bowel wall in Crohn's disease. Novel therapy approaches using anti-CD4 antibodies are thought to be effective in Crohn's disease.
\end{abstract}

Aims-Interleukin 16 (IL-16) has been characterised as a chemokine with selective chemoattraction for CD4+ inflammatory $T$ cells. In this study, cellular expression of IL-16 in Crohn's disease and ulcerative colitis was investigated.

Methods-Expression of IL-16 was analysed in tissue samples of Crohn's disease, ulcerative colitis, and normal controls by applying reverse transcription-polymerase chain reaction, non-radioactive in situ hybridisation, and immunohistochemistry. Double staining methods were used to characterise cells expressing IL-16. The amount of infiltrating CD4+ cells was determined by immunohistochemistry and correlated with the corresponding IL-16+ cell number by step sections.

Results-An increased number of IL-16+ cells in Crohn's disease in comparison with ulcerative colitis and control probes was demonstrated. IL-16 was expressed by CD4 and CD8 positive T cells. In addition, in active Crohn's disease there was a substantial number of IL-16 positive mast cells. The increased number of CD4+ lymphocytes correlated positively with the increased number of IL-16 positive cells in Crohn's disease.

Conclusion-Our results demonstrate that increased expression of IL-16 in T cells and mast cells in active Crohn's disease is associated with increased numbers of CD4+ lymphocytes. Local expression of IL-16 seems to play a significant role in the initiation and persistence of the inflammatory process in Crohn's disease, presumably by IL-16 mediated recruitment of CD4+ cells, mostly lymphocytes, into the bowel wall.

(Gut 2001;49:795-803)

Keywords: Crohn's disease; interleukin 16; inflammation; chemotaxis

The immune alterations initiating and maintaining Crohn's disease (CD) as a chronic inflammatory disorder are still poorly understood. Various hypothesis have been proposed to explain the aetiology and pathogenesis of $\mathrm{CD}$, ranging from exposure to an infective agent to aberrant $\mathrm{T}$ cell regulation. ${ }^{12}$ Chronic inflammatory changes in CD include focal lymphocytic infiltrates within the lamina propria and the submucosa, where granulomas with Langhans' type multinucleated giant cells can also be observed. ${ }^{3}$ The focal lymphocytic aggregates frequently demonstrate a perivascular distribution, predominantly around small submucosal vessels. These infiltrates consist mainly of naive CD4+ lymphocytes ${ }^{45}$ expressing the activation markers CD25 and HLA-DR admixed with scattered freshly migrated monocytes and/or macrophages. ${ }^{3}$ The increased number of CD4+ lymphocytes in intestinal lesions suggests that $\mathrm{T}$ cells are responding to antigenic stimulation and contribute to the local inflammatory process. ${ }^{67}$ This assumption is further supported by studies demonstrating CD4+ $\mathrm{T}$ cells as the major cellular source of proinflammatory cytokines such as interferon $\gamma$, interleukin (IL)-2, and tumour necrosis factor $\alpha$ in $\mathrm{CD}$, representing a so-called TH-1 immune response. ${ }^{1}$ In addition, it has been shown that clinical improvement in CD can be achieved by reduction of activated $\mathrm{T}$ cells by administration of immunosuppressive agents such as cyclosporin A or systemic anti-CD4 antibody. $^{8}$

Because of the regulatory role of CD4+ T cells in CD, study of the mechanisms responsible for accumulation of these cells is of primary importance. IL-16, originally described as lymphocyte chemoattractant factor, serves as the natural ligand of the CD4 molecule. ${ }^{9}$ Thus apart from other cytokines and chemokines, IL-16 can selectively attract CD4+ cells, including $\mathrm{T}$ cells, monocytes, dendritic cells, and neutrophilic granulocytes. ${ }^{10-12}$ In addition to its function as a chemokine, IL-16 stimulates expression of the high affinity IL-2 receptor (IL-2R; CD25) and MHC class II on resting T cells. $^{910}$ Previous studies have shown that IL-16 is produced by a variety of inflammatory cells, including lymphocytes, ${ }^{13}$ mast cells, ${ }^{14}$ and eosinophilic granulocytes, ${ }^{15}$ and epithelial cells such as keratinocytes ${ }^{16}$ and airway epithelial cells. ${ }^{17}$

Abbreviations used in this paper: IL, interleukin; $\mathrm{CD}$, Crohn's disease; UC, ulcerative colitis; NIGD, non-inflammatory gut disorder; RT-PCR, reverse transcription-polymerase chain reaction; $\mathrm{mAb}$, monoclonal antibody; FITC, fluorescein isothiocyanate. 
The biological properties of IL-16 prompted us to hypothesise that IL-16 may be involved in accumulation of CD4+ lymphocytes within the inflammatory affected bowel in CD. The main objective of this study was to characterise and determine the phenotype of inflammatory cells expressing IL-16 at the protein and RNA levels, as evaluated by immunohistochemistry and non-radioactive in situ hybridisation, respectively. Furthermore, the number of cells expressing IL-16 was correlated with the number of CD4+ lymphocytes in CD. Our results provide evidence that increased expression of IL-16 by lymphocytes and mast cells is involved in recruitment of CD4+ lymphocytes in CD.

\section{Methods}

TISSUE SAMPLES

Surgical specimens derived from involved areas of the large intestine of 10 patients with active $\mathrm{CD}$ were studied. CD was active in all patients, as confirmed by clinical features, laboratory parameters, as well as macroscopic and histopathological alterations. All patients underwent surgical intervention because of failure of medical treatment. As controls, surgical specimens from the gut of five patients suffering from therapy resistant ulcerative colitis (UC) (table 1) as well as macroscopic and microscopic uninvolved large bowel tissues from five patients with non-inflammatory gut disorder (NIGD) were used (three colon carcinoma and two diverticular disease). For routine morphological analysis, immunohistochemistry, and non-radioactive in situ hybridisation, appropriate tissue specimens were fixed in formalin and embedded in paraffin. Additional representative samples were snap frozen in liquid nitrogen, stored at $-80^{\circ} \mathrm{C}$, and used for RNA isolation.

RNA EXTRACTION AND REVERSE

TRANSCRIPTION-POLYMERASE CHAIN REACTION (RT-PCR)

RNA was isolated from cryoconserved tissue samples using TriReagent according to the manufacturer's instructions (Sigma, Deisenhofen, Germany) and finally obtained in $30 \mu \mathrm{l}$ RNase free water. RNA content was determined spectrophotometrically. RNA $(1 \mu \mathrm{g})$ was used for reverse transcription after a DNase (FPLC-pure DNaseI; Pharmacia, Freiburg, Germany) digestion step. cDNA synthesis was performed in a total volume of $20 \mu \mathrm{l}$ RNase free water including $1.5 \mu \mathrm{M}$ oligo-dT primer, 0.4 $\mathrm{mM}$ of each deoxynucleotidetriphosphate (both MBI Fermentas, St Leon-Rot, Germany), and $200 \mathrm{U}$ of reverse transcriptase (SuperScriptII; Gibco, Karlsruhe, Germany).

The oligonucleotide primer sequences were determined manually according to the published sequences in GenBank for $\beta$-actin (X00351) and IL-16 (M90391). Polymerase chain reaction (PCR) conditions were as follows: $\beta$-actin ( $\beta$-actin-fw-primer: $5 '-$ CTA CAATGAGCTGCGTGTGGC-3'; $\beta$-actin -rev-primer: 5'-CAGGTCCAGACGCAGGAT GGC -3'; product size: $270 \mathrm{bp}$ ) three minutes at $95^{\circ} \mathrm{C}, 35$ cycles of 40 seconds at $95^{\circ} \mathrm{C}, 45$ seconds at $57^{\circ} \mathrm{C}, 1.5$ minutes at $72^{\circ} \mathrm{C}$, followed by a final extension step of seven minutes at $72^{\circ} \mathrm{C}$; IL-16 (IL-16-fw-primer: 5'- ATG CCCGACCTCAACTCCTCCACT -3'; IL16-rev-primer: 5'-GCCACCCAGCTGC AAGATTTC -3'; product size: $261 \mathrm{bp}$ ) three minutes at $95^{\circ} \mathrm{C}, 35$ cycles of 40 seconds at $95^{\circ} \mathrm{C}, 40$ seconds at $62^{\circ} \mathrm{C}$, one minute at $72^{\circ} \mathrm{C}$, and final elongation of seven minutes at $72^{\circ} \mathrm{C}$. The PCR products were visualised on $1 \%$ agarose gels by staining with ethidium bromide. To exclude amplification of genomic sequences, PCR primers were designed to amplify cDNA fragments that span at least one intron of the corresponding gene. cDNA from a human lymph node was used as a positive control template for each primer pair. Negative controls with water instead of cDNA were always included. A PCR reaction was considered to be positive when a single band of correct product length could be detected. Amplification of correct PCR products was controlled by asymmetric restriction enzyme digestion and sequencing with an ABI310 automatic sequencer using the rhodaminedye-terminator kit according to the manufacturer's instructions (Perkin Elmer, DarmstadtWeiterstadt, Germany).

\section{CLONING OF PCR PRODUCTS}

For generation of the IL-16 riboprobe for quantitative real time RT-PCR or in situ hybridisation, PCR products were cloned into the blunt end SmaI restriction site of the transcription vector pBluescript II KS plasmid. Briefly, blunt end PCR products were generated using Vent polymerase (Pharmacia) according to the PCR cycling conditions, as mentioned above. After micro spin column purification (Pharmacia, Heidelberg, Germany), the blunt end PCR products were ligated into a SmaI restricted pBluescript II KS plasmid using T4-DNA-ligase at $16^{\circ} \mathrm{C}$ overnight and transformed into the $\mathrm{CaCl}_{2}$ competent Escherichia coli strain DH5a. After propagation under standard culture conditions the plasmids were isolated using the alkaline lysis procedure. Cloning of IL-16 specific PCR fragments was confirmed by cycle sequencing with the rhodamine-dye-terminator kit using an $\mathrm{ABI} 310$ sequencer according to the manufacturer's instructions (Perkin-Elmer). Riboprobes were generated by in vitro transcription using T3 or T7 polymerase (Boehringer, Mannheim, Germany). The amount of cRNA transcripts was monitored by $1 \%$ agarose gel electrophoresis and determined spectrophotometrically.

REAL TIME QUANTITATIVE RT-PCR ANALYSIS Quantification of IL-16 mRNA expression by RT-PCR was performed on an iCycler iQ real time detection system (Bio-Rad, Hercules, California, USA). For RT-PCR, a one step RT-PCR kit (Qiagen, Hilden, Germany) was used. The $15 \mu \mathrm{l}$ reaction from this kit was supplemented with $150 \mathrm{ng}$ total cellular RNA, 0.6 $\mu \mathrm{M}$ each of the gene specific primers, $4 \mathrm{U}$ 
RNase inhibitor (Promega, Mannheim, Germany), and $0.5 \mu \mathrm{l}$ of SYBRgreen I dye (Molecular Probes, MoBiTec, Göttingen, Germany), and diluted in $1 \times$ RT-PCR buffer (Qiagen) to $12.5 \times$. Dilution was checked spectrophotometrically at $260 \mathrm{~nm}$. The final concentration of SYBRgreen I dye was $0.4 \times$. The reaction mix was loaded into rows of eight $200 \mu 1$ PCR reaction tubes (Sarstedt, Nümbrecht, Germany) and covered with optical sealing tape (Bio-Rad). The thermal cycling proceeded as follows: $50^{\circ} \mathrm{C}$ for 30 minutes reverse transcription followed by 15 minutes at $95^{\circ} \mathrm{C}$ for denaturation of reverse transcriptase and activation of HotStar Taq polymerase. A maximum of 50 PCR cycles were run in the following profile: initial denaturation at $95^{\circ} \mathrm{C}$, annealing at $62^{\circ} \mathrm{C}$, and extension at $72^{\circ} \mathrm{C}$ for 30 seconds each. Acquisition of fluorescence signals was monitored on the iCycler and terminated when all reactions reached an amplification plateau and template free control remained at baseline levels. A PCR standard curve was generated using the same reaction mix including in vitro generated IL-16 cRNA (dilution range from 1 to 1000 attomols) instead of total cellular RNA. Data analysis was performed with iCycler iQ real time detection system software (Bio-Rad). Results derived from the PCR standard curve for IL-16 mRNA expression are given in attomoles per $\mu \mathrm{g}$ total cellular RNA.

To verify that only specific PCR products evoked fluorescence signals, a melting curve of PCR products was obtained in a cycler programme of denaturation $\left(95^{\circ} \mathrm{C}\right)$, renaturation $\left(50^{\circ} \mathrm{C}\right)$, and a temperature ramp from $60^{\circ} \mathrm{C}$ to $95^{\circ} \mathrm{C}$ with $0.5^{\circ} \mathrm{C}$ increments for 10 seconds. Melting peaks were related to PCR product size on $1 \%$ agarose gels.

IMMUNOHISTOCHEMISTRY

Paraffin embedded sections were immunostained applying the biotin-streptavidinperoxidase method according to the manufacturer's instructions (Dako, Hamburg, Germany). For detection of IL-16 (IgG1 hybridoma supernatant, gift from $G$ Schluesener, Tübingen, Germany) ${ }^{18}$ and CD4 (Novocastra, Dossenheim, Germany), sections were pretreated by repeated boiling in citrate buffer $(\mathrm{pH} 6.1)$ in a microwave $(700 \mathrm{~W}, 5 \times 3$ minutes). After cooling to room temperature, non-specific binding was blocked with $20 \%$ rabbit serum (CC-Pro, Frankfurt/Main, Germany) in $0.05 \mathrm{~mol} / 1$ Tris $/ \mathrm{HCl}$ buffer- $\mathrm{NaCl}$ solution (TBS, $\mathrm{pH}$ 7.4) followed by incubation with the primary antibody overnight at $4^{\circ} \mathrm{C}$ in a humidified chamber. After rinsing in TBS, slides were incubated for 30 minutes with a biotinylated rabbit antimouse Ig polyclonal antibody (Dako) followed by incubation with a streptavidin-biotin-complex coupled with horseradish peroxidase (Dako) for 20 minutes at room temperature. Peroxidase activity was visualised using diaminobenzidine as the chromogen. In control reactions primary antibodies were omitted.

To characterise in situ coexpression of IL-16 by CD4+ or CD8+ T cells and mast cells, dual colour digital confocal laser microscopy on paraffin embedded sections was performed. Pretreatment of the deparaffinised slides was performed as mentioned above. The IL-16 monoclonal antibody (mAb) was applied first and incubated overnight in a humidified chamber at $4^{\circ} \mathrm{C}$ followed by incubation with rhodamine-red-X conjugated $\mathrm{F}(\mathrm{ab})$ fragments of rabbit antimouse Ig (Dianova, Hamburg, Germany) at saturating concentrations for 60 minutes at room temperature. Subsequently, mAbs against CD4, CD8 (Novocastra), and tryptase (for characterisation of mast cells; Dako) were applied overnight at $4^{\circ} \mathrm{C}$. For detection of tryptase the mAb was directly labelled with fluorescein isothiocyanate (FITC) using a FITC labelling kit according to the manufacturer's instructions (Boehringer). mAbs against CD 4 and CD 8 were detected by indirect immunofluorescence using $\mathrm{F}(\mathrm{ab})_{2}$ fragments of indocarbocyanine 2 labelled goat antimouse immunoglobulins (Dianova) for 60 minutes at room temperature. After each incubation, sections were thoroughly washed in TBS and prior to examination embedded in fluoromount fluorescent mounting media to prevent fading (Dako). Omission of first step antibodies served as negative controls. Sections were analysed using the Leica (Heidelberg, Germany) TCS NT laser scanning system mounted on an Olympus Opticals (Tokyo, Japan) BX50 WI microscope.

\section{IN SITU HYBRIDISATION}

For in situ hybridisation, paraffin sections were mounted on slides coated with 3-aminopropyltriethoxysilane (Sigma) under RNAse free conditions. Slides were dried at $37^{\circ} \mathrm{C}$ overnight.

Digoxigenin labelled cRNA probes were prepared using a kit, according to the manufacturer's instructions (Boehringer). Briefly, plasmids were linearised with NotI or HindIII, and digoxigenin-11-dUTP labelled antisense and sense probes were generated by in vitro transcription using T3 or T7 polymerase (Boehringer). The amount of transcripts was monitored by $1 \%$ agarose gel electrophoresis. Labelling efficiency was controlled by dot blot analysis of serial probe dilutions.

In situ hybridisation was performed according to the method of Breitschopf and colleagues. ${ }^{19}$ In brief, tissue sections were deparaffinised, rehydrated in serial dilutions of ethanol, and postfixed in 4\% TBS buffered paraformaldehyde. Samples were permeabilised using proteinase $\mathrm{K}(10 \mu \mathrm{g} / \mathrm{ml})$ for $30 \mathrm{~min}$ utes at $37^{\circ} \mathrm{C}$. Digestion was stopped by washing the samples in phosphate buffered saline $(\mathrm{pH}$ 7.4). For blocking of endogenous alkaline phosphatase, slides were incubated with $0.25 \%$ acetic anhydride and dehydrated in serial dilutions of ethanol. Digoxigenin labelled riboprobes were diluted in hybridisation buffer (Amersham, Braunschweig, Germany). After application of sense or antisense probes, samples were covered with sterile coverslips and placed on a hot plate at $85^{\circ} \mathrm{C}$ for five minutes for probe and target denaturation. Hybridisation was performed overnight at $62^{\circ} \mathrm{C}$ in 
a sealed humidified chamber containing 50\% formamide. Non-specific binding or unbound probes were removed by the following posthybridisation washes: $1 \times \mathrm{SSC} / 0.1 \% \mathrm{SDS}$ at room temperature $(2 \times 5$ minutes $)$ and $0.2 \times \mathrm{SSC} / 0.1 \% \mathrm{SDS}$ at $60^{\circ} \mathrm{C}(2 \times 10$ minutes $)$ followed by RNase digestion $(20 \mu \mathrm{g} / \mathrm{ml}$; Gibco, Karlsruhe, Germany) for 30 minutes at $37^{\circ} \mathrm{C}$. Finally, sections were washed in TBS containing $0.1 \%$ Tween 20 (Boehringer).

Hybridisation signals were detected using a sheep polyclonal antibody $\mathrm{F}(\mathrm{ab})_{2}$ fragment against digoxigenin conjugated with alkaline phosphatase (1:500; Boehringer). Alkaline phosphatase activity was visualised using 5-bromo-4-chloro-3-indolyl phosphate as substrate and nitroblue tetrazolium as coupler (Boehringer). For each tissue section sense riboprobes served as controls.

In some cases hybridised specimens were incubated with mAbs $\mathrm{Ki}-\mathrm{M} 1 \mathrm{P}$ recognising monocytes/macrophages ${ }^{20} \mathrm{Ki}-\mathrm{M} 4 \mathrm{P}$ recognising follicular dendritic cells (kindly provided by
Professor MR Parwaresch, Kiel, Germany), ${ }^{21}$ CD3 for T cells, CD20 for B cells, NK-1 for natural killer cells, and $\mathrm{S} 100$ protein recognising interdigitating dendritic cells (Dako) followed by a rabbit antimouse Ig FITC (Dako) for evaluation by immunofluorescence.

COUNTING AND DATA ANALYSIS

Evaluation of immunoreactivity was performed on step sections stained for IL-16 and CD4 by two blinded evaluators. Corresponding areas of the step sections were marked and high power fields were counted with an eyepiece graticule at $400 \times$ magnification. The results were expressed as mean counts from a total of five high power fields per slide. The within observer coefficient of variation for repeated counts was less than $5 \%$.

Data were analysed using a statistical package (Systat version 5.1; Systat Inc, Evanston, USA). Statistical comparisons were performed using ANOVA, and subsequent comparisons were made using the Mann-Whitney $\mathrm{U}$ test;
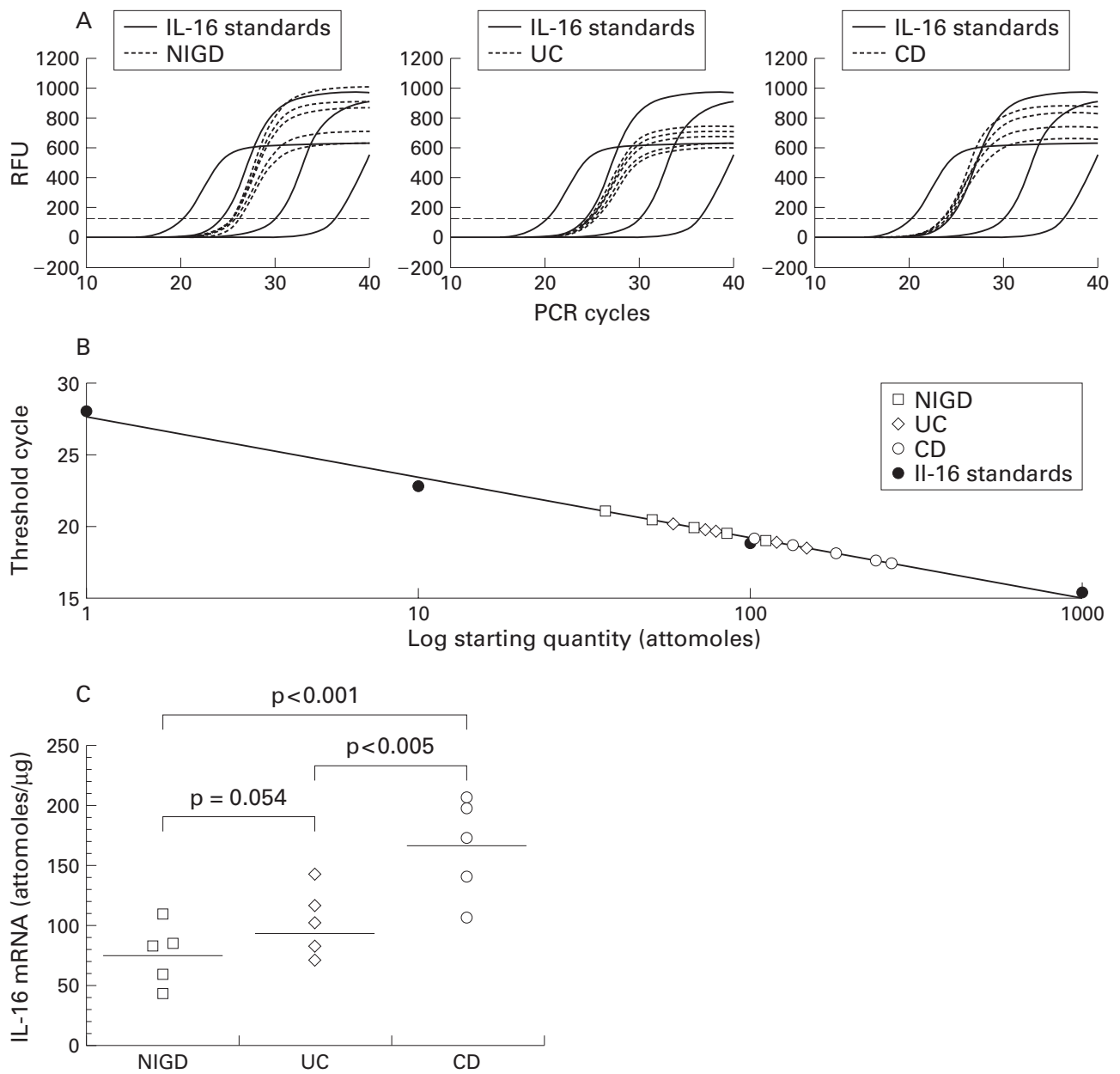

Figure 1 Quantitative real time reverse transcription-polymerase chain reaction (RT-PCR) analysis of interleukin 16 (IL-16) mRNA. Total RNA was analysed for IL-16 mRNA expression by quantitative RT-PCR on RNA from tissue samples affected by Crohn's disease (CD) $(n=5)$, ulcerative colitis (UC) $(n=5)$, and non-inflammatory gut disorder $(N I G D)(n=5)$. The amount of IL-16 mRNA expression per $\mu g$ total $m R N A$ was derived from a standard curve using increasing amounts of in vitro generated IL-16 cRNA. Threshold cycle values of IL-16 specific amplification products were deducted from changes in SYBR Green fluorescence (RFU) during each PCR cycle for IL-16 standards and IL-16 samples from $C D(A$, right), $U C$ ( $A$, centre), and controls ( $A$, left). The threshold (broken line) was set according to RFU variations in early PCR cycles. The calibration curve was derived from threshold cycle values (shown in A) for each known amount of IL-16 cRNA standard (1,10,100, and 1000 attomoles) (B). (C) In CD, significantly higher expression of $I L-16 m R N A$ was found compared with UC $(p<0.005)$ and NIGD $(p<0.001)$ whereas levels of IL-16 mRNA expression in UC versus NIGD proved not to be statistically significant $(p=0.054)$. Data are shown for one of three independent experiments. 
$\mathrm{p}<0.05$ was considered statistically significant. Correlation was performed using Spearman's rank correlation test.

\section{Results}

QUANTITATIVE RT-PCR OF IL-16 mRNA IN CD

IL-16 mRNA expression was analysed in tissue samples affected by active CD $(n=5)$, UC $(n=5)$, and from normal controls without signs of inflammation $(n=5)$ by RT-PCR with oligonucleotide primers specific for the human IL-16 cDNA. As an internal control RT-PCR for the housekeeping gene $\beta$-actin was performed (data not shown). IL-16 specific products were amplified from mRNA probes isolated from all tissue samples investigated.

For quantification of IL-16 mRNA expression in tissue samples, a method of real time quantitative RT-PCR was established using iCycler technology. IL-16 mRNA levels in equal amounts of total RNA from tissue samples were calculated by reference to a standard curve which was obtained by one step RT-PCR containing different concentrations of in vitro generated IL-16 cRNA (IL16standards), with a dilution range of 1 to 1000 attomoles (fig 1A, B). Quantification results are given as attomoles per $\mu$ g total cellular RNA of

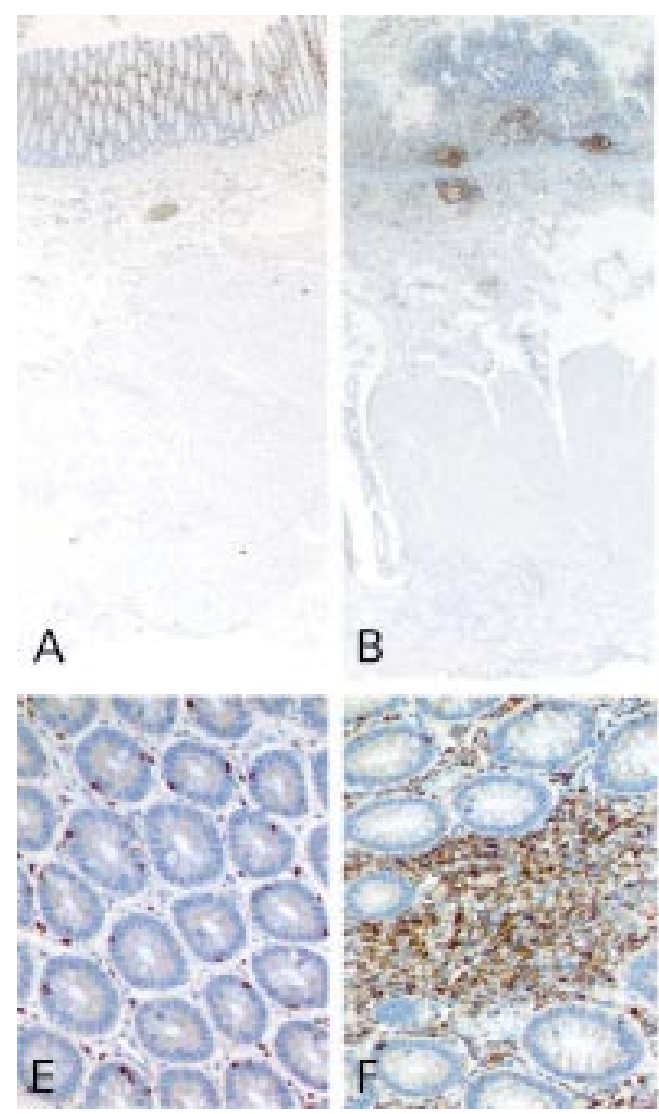

each investigated tissue sample. In total RNA isolated from tissues with active CD, a significant increase in expression of IL-16 mRNA was determined compared with UC $(p<0.005)$ and NIGD $(p<0.001)$ and expression of IL-16 mRNA in UC was moderately higher than that in NIGD ( $p=0.054$ ) (fig $1 C$ ).

DISTRIBUTION PATTERN OF IL-16 EXPRESSION WITHIN THE BOWEL WALL

In further experiments, RT-PCR findings were confirmed by immunohistochemistry using an IL-16 specific antibody and by non-radioactive in situ hybridisation. Both methods showed comparable results. In NIGD, IL-16 expression was virtually restricted to a few cells of the lamina propria and within the surface epithelium (fig $2 \mathrm{~A}, \mathrm{E}$ ). The same pattern of IL-16 expression was observed for specimens affected by UC but showing an increased number of IL-16 positive cells within the lamina propria (fig 2B). In CD, IL-16 was found to be expressed within the inflammatory infiltrate of the entire bowel wall. Within the mucosa, increased numbers of positive cells were found within the lymphocytic infiltrates of the lamina propria (fig 2C, F) and within the epithelium

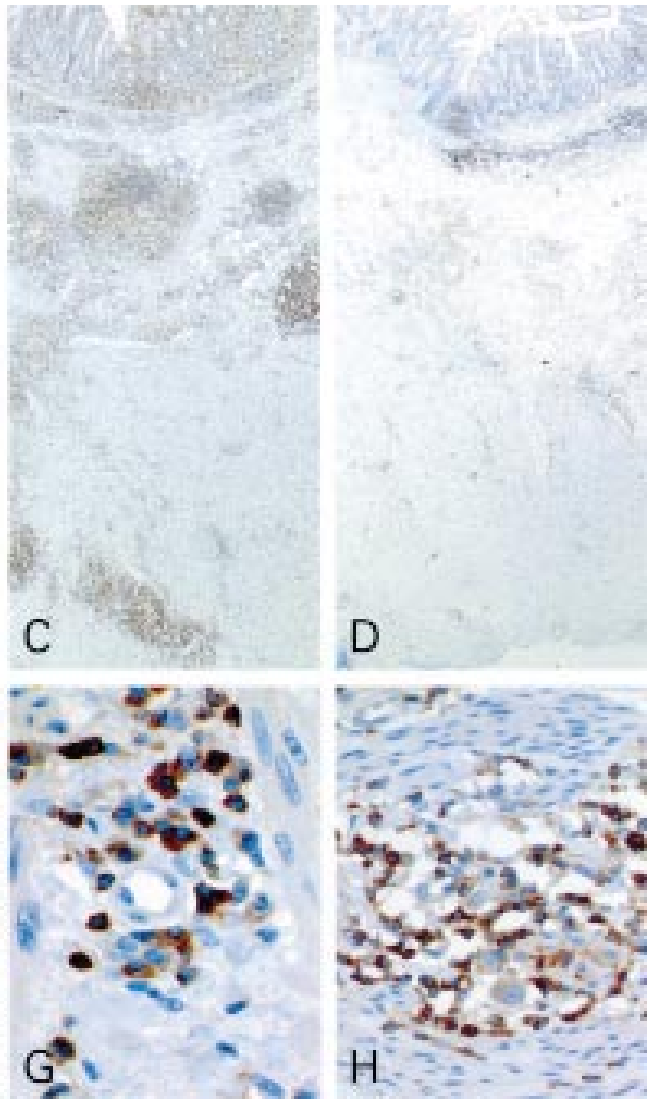

Figure 2 Immunohistochemistry of interleukin 16 (IL-16) protein expression. Sectional images of the bowel wall of non-inflammatory disease demonstrated that expression of IL-16 was restricted to the mucosa $(A)$. In ulcerative colitis (UC), numerous IL-16 positive cells were found within the mucosa and within the adjacent submucosal tissue (B). In tissue specimens of active Crohn's disease (CD), numerous IL-16 positive cells were found within inflammatory aggregates of the entire bowel wall $(C)$ whereas in sections from macroscopically uninvolved bowel of patients suffering from CD, IL-16 positive cells were predominantly restricted to the mucosa and submucosal tissue $(D ; A-D \times 20)$. In non-inflammatory disorder of the large bowel, IL-16 expression was found to be restricted to a few lamina propria lymphocytes as well as to intraepithelial lymphocytes $(E, \times 200)$. In tissue specimens of $C D$, aggregates of lymphocytes showed strong expression of $I L-16$ protein in the lamina propria in addition to some intraepithelial lymphocytes $(F, \times 200)$. In submucosal layers of $C D$, $I L-16$ positive cells were predominately found in the vicinity of vessels $(G, \times 600)$. Histiocytes of $C D$ granulomas were constantly negative for IL-16 in contrast with interspersed lymphocytes $(H, \times 400)$. 

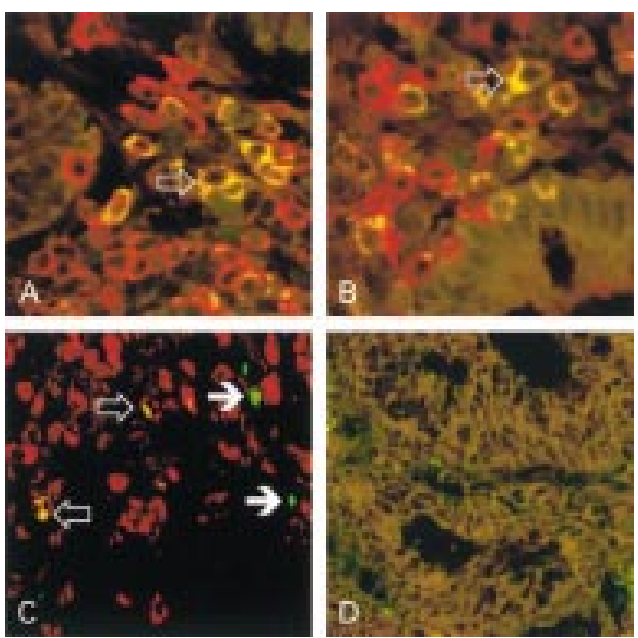

Figure 3 Cellular expression of interleukin 16 (IL-16) in Crohn's disease (CD). Two colour immunofluorescence was used to determine expression of IL-16 (rhodamine-red X, red fluorescence) by double labelling with antibodies for $C D 4(A, \times 600), C D 8(B, \times 600 ;$ both green fluorescence), or mast cell specific tryptase $(C ; \times 400$, green fluorescence). Cells showing coexpression of IL-16 were visualised after

digital negative colour subtraction of the single fluorescence images by a yellow colour (open arrows). Most IL-16 positive cells were found to express either CD4 $(A)$ or $C D 8$ (B), representing the $C D 3+T$ cell population.

Additionally, IL-16 expression was observed in mast cells

(C) whereas numerous mast cells showed no coexpression of IL-16 (closed arrows). Non-specific staining was excluded by negative controls with irrelevant primary antibody $(D$, $\times 400)$.

representing intraepithelial lymphocytes. Furthermore, numerous IL-16 positive cells were observed adjacent to blood vessels representing freshly migrated cells (fig 2G). The perivascular pattern was predominately found in the deeper layers of the bowel wall comprising the submucosa, muscularis propria, and subserosal tissue. Granulomas in CD did not demonstrate expression of IL-16 in the central epitheloid and giant cells in contrast with the surrounding lymphocytes (fig $2 \mathrm{H}$ ).

CELLULAR EXPRESSION OF IL-16

To characterise the phenotype of inflammatory cells that express IL-16, double labelling experiments combining immunofluorescence by laser scanning microscopy or nonradioactive in situ hybridisation with immunofluorescence were performed. Most IL-16
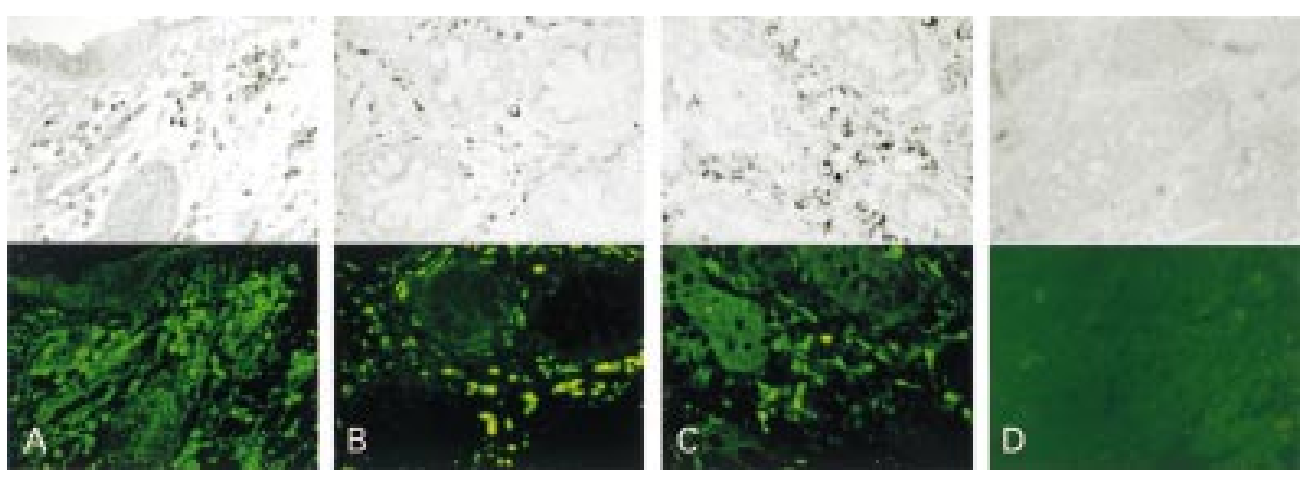

positive cells were identified as CD4 (fig 3A) or CD8 (fig 3B) positive $T$ cells. In addition, increased expression of IL-16 by mast cells was found in cases of CD (fig 3C). IL-16 positive mast cells were observed within the lamina propria and in the vicinity of blood vessels within the submucosa or deeper layers of the bowel wall. Furthermore, expression of IL-16 was observed in very few eosinophilic granulocytes. Expression of IL-16 by neutrophilic granulocytes could not be found. Also, expression of IL-16 protein or mRNA could not be found by natural killer cells (detected by the $\mathrm{mAb} \mathrm{NK}-1$ ), macrophages (detected by the mAb Ki-M1P), dendritic cells of either $\mathrm{T}$ or $\mathrm{B}$ accessory function (detected by the mAbs to S-100 protein and Ki-M4P, respectively), or B lymphocytes (detected by the mAb CD20) (fig 4). By applying non-radioactive in situ hybridisation, we found a few basal epithelial crypt cells displaying IL-16 expression. These cells were found in comparable numbers in $\mathrm{CD}$, UC, and NIGD. Applying immunohistochemistry however, IL-16 expression by these cells could not be confirmed at the protein level.

The increased number of IL-16+ cells within the mucosa of CD in comparison with UC and NIGD proved to be statistically significant $(p<0.001)$ whereas there was no significant difference between the number of IL-16 positive cells in cases of UC and NIGD $(p=0.232)$ (fig 5A). Further investigation of tissue samples from macroscopically uninvolved mucosa compared with inflamed colonic mucosa from the same patient revealed a significant increase in IL-16 positive cells $(p<0.001)$ whereas there was no significant difference between the number of IL-16 positive cells in uninvolved mucosa of $C D$ versus UC $(p=0.1866)$ and NIGD $(p=0.142$; data not shown). Furthermore, a significant correlation was found between numbers of CD4+ lymphocytes and numbers of IL-16+ cells $\left(r^{2}=0.77, \mathrm{p}<0.001\right)$ (fig $\left.5 \mathrm{~B}\right)$. As all tissue specimens were exclusively derived from the mucosa of different segments of the large bowel, variations in results caused by differences in the cellular composition of the bowel segment investigated (such as comparing specimens from the small intestine with those derived from the

Figure 4 In situ interleukin 16 (IL-16) $m R N A$ expression in Crohn's disease (CD). IL-16 mRNA was detected by non-radioactive in situ hybridisation combined with indirect immunofluorescence for the $T$ cell marker $C D 3(A, \times 200)$, the monocyte/macrophage marker $K i-M 1 P(B, \times 200)$, and $S-100$ protein recognising dendritic cells $(C, \times 200)$. Numerous $I L-16 m R N A$ positive cells were found within the lamina propria in $C D$. The majority of IL-16 $m R N A$ positive cells where found to be $T$ cells showing coexpression for CD3 (A). No expression of IL-16 mRNA was observed by Ki-M1P positive macrophages (B) or $S-100$ protein positive dendritic cells $(C)$. Negative controls for in situ hybridsation with sense riboprobe $(D$, upper, $\times 200)$ and immunofluorescence with irrelevant primary antibody $(D$, lower, $\times 200)$. 
A

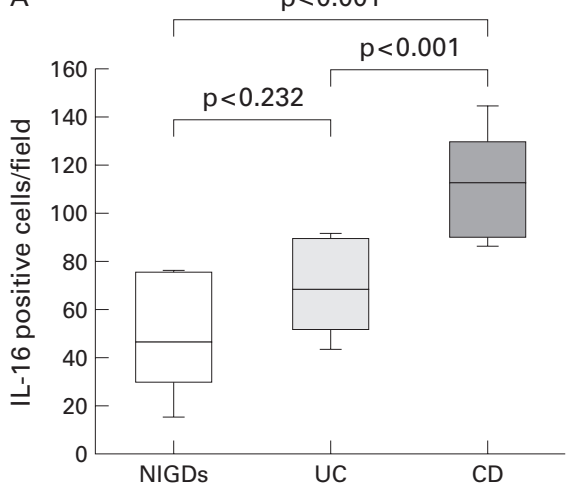

B

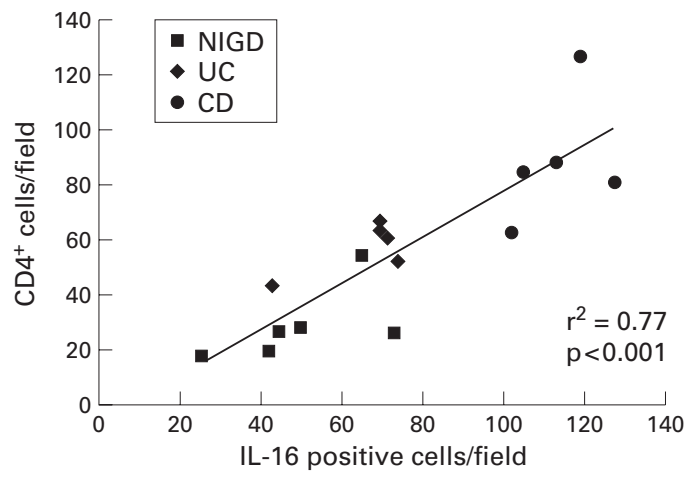

Figure 5 Quantitative analysis of interleukin $16(I L-16)+$ and CD4+ cell numbers in non-inflammatory gut disorder (NIGD), ulcerative colitis (UC), and Crohn's disease (CD). (A) Number of IL-16 positive cells within the lamina propria in tissue specimens from patients with NIGD, UC, and CD. Results are expressed as number of positive cells per field. IL-16 protein positive cells were significantly increased in CD compared with NIGD $(p<0.001)$ and UC $(p<0.001)$. No significant difference was observed between UC and NIGD ( $p=0.232)$. (B) Significant correlations between IL-16+cells and CD4+ cell infiltration in NIGD, UC, and CD.

colon) were excluded. In addition, differences in the number of IL-16 positive cells as a result of different therapy modalities, such as application of non-steroid therapeutics or administration of local or systemic steroids, were not observed when comparing patients suffering from CD and UC (table 1).

\section{Discussion}

The inflammatory infiltrate in active $\mathrm{CD}$ is characterised by an increased number of lymphocytes expressing the CD4 antigen. CD4+ $\mathrm{T}$ cells belong either to the freshly migrated CD45RA+ subtype, representing naive $\mathrm{T}$ cells, or to $\mathrm{T}$ cells expressing CD45RO, representing the memory subtype. ${ }^{3}$ It is hypothesised that cell renewal by migration of naive $T$ cells into the inflamed bowel wall plays an important part in perpetuation of the inflammatory process in $\mathrm{CD} .^{3}$ However, the precise mechanisms responsible for recruitment of CD4+ $\mathrm{T}$ cells within the inflamed gut in $\mathrm{CD}$ are still unclear. To investigate the potential role of IL-16, a novel cytokine serving as a specific chemokine for CD4+ cells, we analysed expression of IL-16 at the protein and RNA levels in CD using immunohistochemistry and non-radioactive in situ hybridisation, respectively. Furthermore, cell types expressing

Table 1 Clinical data, including drug treatment and localisation of tissue samples, of cases analysed in the study

\begin{tabular}{|c|c|c|c|c|c|}
\hline Patient No & $\operatorname{Age}(y)$ & Sex & $\begin{array}{l}\text { Duration of } \\
\text { disease (y) }\end{array}$ & Localisation & Therapy \\
\hline CD1 & 27 & M & 13 & Descendingcolon & Prednisolone \\
\hline $\mathrm{CD} 2$ & 35 & $\mathrm{~F}$ & 14 & Sigmoidcolon & Mesalazine \\
\hline CD3 & 59 & $M$ & 7 & Ascendingcolon & Prednisolone \\
\hline CD4 & 37 & $\mathrm{~F}$ & 8 & Transversecolon & Prednisolone \\
\hline CD5 & 49 & $\mathrm{~F}$ & 5 & Ascendingcolon & Mesalazine \\
\hline CD6 & 46 & $\mathrm{M}$ & 11 & Ascendingcolon & Prednisolone \\
\hline CD7 & 25 & M & 5 & Ascendingcolon & Budenoside/mesalazine \\
\hline CD8 & 18 & M & 9 & Ascendingcolon & Budenoside/mesalazine \\
\hline CD9 & 36 & M & 5 & Rectum & Mesalazine \\
\hline CD10 & 34 & $\mathrm{M}$ & 2 & Ascendingcolon & None \\
\hline $\mathrm{UC1}$ & 46 & $\mathrm{~F}$ & 22 & Transversecolon & 5-ASA \\
\hline $\mathrm{UC} 2$ & 26 & $\mathrm{~F}$ & 9 & Sigmoidcolon & 5-ASA/prednisolone \\
\hline UC3 & 55 & M & 11 & Rectum & 5-ASA/prednisolone \\
\hline UC4 & 35 & $M$ & 11 & Sigmoidcolon & Prednisolone \\
\hline UC5 & 62 & $\mathrm{M}$ & 8 & Transversecolon & 5-ASA/prednisolone \\
\hline
\end{tabular}

CD, Crohn's disease; UC, ulcerative colitis; 5-ASA, 5-aminosalicylic acid.
IL-16 in CD were characterised by dual colour immunofluorescence and confocal laser scanning microscopy or non-radioactive in situ hybridisation combined with indirect immunofluorescence.

Our results showed a statistically significant increase in IL-16 mRNA (figs 1,4) and IL-16 protein positive cells in CD in comparison with UC and NIGD (figs 2, 5). Interestingly, we did not find increased numbers of IL-16 positive cells in uninvolved mucosa of patients suffering from active CD compared with UC or NIGD. Thus increased expression of IL-16 seems to be restricted to sites of inflamed mucosa in CD. Consistent with prior observations, lesion biopsies from patients with acute CD were characterised by an increased number of infiltrating CD4+ T cells within the inflammatory affected bowel wall. ${ }^{42}$ In addition, our results provided evidence for a positive correlation between the number of infiltrating CD4+ lymphocytes and the number of IL-16+ cells in CD, UC, and biopsies from NIGD (fig 5). To exclude differences caused by variations in cell numbers within the lamina propria from different anatomical sites, all tissue specimens were obtained from the large bowel of patients suffering from active CD, UC, or NIGD. Furthermore, differences resulting from different therapy modalities such as application of nonsteroid therapeutics or administration of local or systemic steroids were not observed when comparing patients suffering from CD or UC (table 1).

By applying double labelling procedures and immunostaining of serial sections, we showed that different inflammatory cell types comprising CD 4 and CD8 positive $\mathrm{T}$ cells, mast cells, and a few eosinophilic granulocytes were responsible for production of IL-16 in CD as well as in UC, and to a lesser extent in NIGD (fig 3). Expression of IL-16 was not observed at the RNA or protein level in neutrophilic granulocytes, natural killer cells, B lymphocytes, monocytes/macrophages, dendritic cells, or fibroblasts, which in recent studies have been shown to partly produce IL-16. ${ }^{917} 23$ 
Originally, IL-16 was found to be expressed by circulating $\mathrm{T}$ cells of the CD4+ and CD8+ subsets. ${ }^{24} \mathrm{CD} 8+\mathrm{T}$ cells constitutively synthesise the bioactive form of IL-16, which is released on stimulation by antigen, mitogen, serotonin, and histamine whereas CD4+ $\mathrm{T}$ cells were found to contain constitutive IL-16 mRNA as well as the $80 \mathrm{kDa}$ putative precursor molecule but not the preformed $14 \mathrm{kDa}$ bioactive protein. CD $4+\mathrm{T}$ cells release the bioactive IL-16 protein following mitogen, antigen, or anti-CD3 stimulation by a process that requires transcription and translation of new protein. ${ }^{11}$ By northern blot analysis, it was shown that IL-16 mRNA expression is constitutively found abundantly in human lymphoid tissue, including lymph node, spleen, and thymus. ${ }^{13}$ Interestingly, IL-16 mRNA transcripts were not detected by northern blot analysis of RNA isolated from tissue specimens of the small and large bowel. ${ }^{13}$ The latter finding is in contrast with our results obtained by RT-PCR (fig 1), in situ hybridisation, and immunohistochemistry (fig 2A) in biopsy specimens from patients with NIGD. This fact may be explained by the different methods and tissue specimens used for investigation of IL-16 mRNA expression. In the present study, IL-16 mRNA expression was determined by one step RT-PCR which is a much more sensitive method compared with northern blot analysis. Furthermore, the tissue specimens investigated in the present study were derived from the mucosa and submucosa, sites which contain a substantial number of IL-16 positive cells in non-inflammatory conditions, but not from deeper layers such as the muscularis propria and subserosa, which are devoid of IL-16 positive cells in the normal bowel. Thus lack of IL-16 mRNA expression in northern blots may be due to low numbers of IL-16 positive cells restricted to the mucosa in non-inflammatory affected bowel. In addition, our results provide evidence that IL-16 predominantly expressed by $\mathrm{CD} 4+$ and $\mathrm{CD} 8+\mathrm{T}$ cells participates in immune homeostasis in the non-diseased state of the mucosa associated lymphatic tissue of the alimentary tract. Expression of IL-16 in epithelial cells of the mucosa, as recently shown for epithelial cells of the respiratory tract ${ }^{1725}$ or keratinocytes, ${ }^{1623}$ was only observed in a few cells of the basal crypts by in situ hybridisation in CD, UC, and NIGD at the same level. This finding was not confirmed for IL-16 protein expression by immunohistochemistry. Epithelial cells of the bowel thus do not seem to contribute to expression of IL-16 in normal or inflammatory affected bowel, which is in contrast with the results observed in atopic asthma and atopic dermatitis. ${ }^{16}{ }^{17}$

Mast cells have been shown to express a wide range of chemokines, some of which possess chemotactic activities for $\mathrm{T}$ cells such as RANTES, IL-8, MCP-1, MIP- $1 \alpha$, and MIP$1 \beta .^{26}$ Recently, the human leukaemic mast cell line HMC-1 was reported to express IL-16 mRNA. ${ }^{14}$ Expression of IL-16 protein was also identified by intracytoplasmic cytokine staining and flow cytometry of cultures from human bone marrow derived mast cells as well as from human mast cell lines. Release of bioactive IL-16 was noted after stimulation. ${ }^{14}$ Furthermore, in a more recent study, mast cells were shown to express IL-16 protein in biopsies of acute atopic asthma where they comprised about $10 \%$ of the total cells expressing IL-16 within the inflammatory infiltrate. ${ }^{17}$ By digital confocal laser scanning microscopy, as well as by double immunohistochemistry (data not shown), we found expression of IL-16 within the cytoplasm of about $40-50 \%$ of the mast cells present in CD (fig 3C). The capacity of mast cells in CD to produce IL-16 provides a possible link between mast cell activation and recruitment of $\mathrm{CD} 4+$ lymphocytes during the inflammatory response in CD. Furthermore, as mast cells are predominantly found in the vicinity of blood vessels, IL-16 expressed by these cells may function in the recruitment of circulating naive CD4+ lymphocytes from the bloodstream. In contrast with other studies, we could not find expression of IL-16 protein or RNA by other cell types such as fibroblasts, ${ }^{9}$ monocytes/macrophages, ${ }^{17}$ or $\mathrm{T}$ accessory dendritic cells. ${ }^{23}$

In this study, we provided evidence for increased expression of IL-16 in CD. The methods used did not allow us to demonstrate selectively the biological activity of IL-16 as the monoclonal IL-16 specific antibody used detects both the $80 \mathrm{kDa}$ precursor and the 14 $\mathrm{kDa}$ bioactive form, as determined by western blot analysis (manuscript in preparation). However, as the increased presence of IL-16 positive cells in CD correlates with increased accumulation of CD4+ cells, the presence and release of biologically active IL-16 seems very likely. Furthermore, Keates and colleagues ${ }^{27}$ recently demonstrated increased expression of IL-16 protein in trinitrobenzene sulphonic acid induced colitis in mice, which represents an animal model of CD believed to be mediated by CD4+ T cells. In this study, administration of a neutralising monoclonal antibody directed against IL-16 substantially reduced trinitrobenzene sulphonic acid induced colonic ulceration, inflammation, and death.

The present study indicates that increased production of IL-16 may be an important factor for recruitment of CD4+ cells in CD. Determining the distribution and expression of IL-16 in the human alimentary tract seems to be important for the design of drug delivery or targets of novel immune therapy approaches, focusing on specific cells that generate signals responsible for recruitment of $\mathrm{CD} 4+$ lymphocytes at sites of inflammation in inflammatory bowel diseases such as CD. For an understanding of the efficacy and immune modulating effects of new therapies, further investigations of the basic mechanisms underlying activation of the CD4 antigen by its natural ligand IL-16 are required. Prior investigations as well as our results provide evidence that production and release of IL-16 results in migration, activation, and maturation of $\mathrm{CD} 4+$ $\mathrm{T}$ lymphocytes in $\mathrm{CD}$, thus initiating and maintaining the chronic inflammatory process. 
We thank Mr K Müller for excellent art work and Mrs K Koch for critically reading the manuscript.

1 Parronchi P, Romagnani P, Annunziato F, et al. Type 1 T-helper cell predominance and interleukin-12 expression
in the gut of patients with Crohn's disease. Am $\mathcal{F}$ Pathol in the gut of patient

2 Gulwani-Akolkar B, Akolkar P, Minassian A, et al. Selective expansion of specific $\mathrm{T}$ cell receptors in the inflammed

3 Burgio V, Fais S, Boirivant M, et al. Peripheral monocyte and naive T-cell recruitment and activation in Crohn's disease. Gastroenterology 1995;109:1029-38.

4 Deusch K, Reich K. Immunological aspects of inflammatory bowel disease. Endoscopy 1992;24:568-77.

5 Lowes J, Jewell D. The immunology of inflammatory bowel disease. Springer Semin Immunopathol 1990;12:251-68.

6 Schreiber S, MacDermott R, Raedler A, et al. Increased activation of isolated intestinal lamina propria mononuclear cells in inflammatory bowel disease. Gastroenterology 1991;101:1020-30.

7 Pallone F, Fais S, Squarcia O, et al. Activation of peripheral blood and lamina propria lymphocytes in Crohn's disease. In vivo state of activation and in vitro response to stimulation as defined by expression of early activation antigens. Gut $1987 ; 28: 745-53$.

8 Stronkhorst A, Radema S, Yong S, et al. CD4 antibody treatment in patients with active Crohn's disease: a phase 1 dose finding study. Gut 1997;40:320-7.

9 Franz J, Kolb S, Hummel K, et al. Interleukin-16, produced by synovial fibroblasts, mediates chemoattraction for CD4+ T lymphocytes in rheumatoid arthritis. Eur f Immunol 1998;28:2661-71

10 Blaschke V, Reich K, Middel P, et al. Expression of the Mycosis fungoides. F Invest Dermatol 1999;113:658-63.

11 Center D, Kornfeld H, Cruikshank W. Interleukin-16 and its function as a CD4 ligand. Immunol Today 1996;17:47681.

12 Cruikshank W, Center D, Nisar N, et al. Molecular and functional analysis of a lymphocyte chemoattractant factor: association of biological function with $\mathrm{CD} 4$ expression. Proc Natl Acad Sci USA 1994;91:5109-13.

13 Chupp G, Wright E, Wu D, et al. Tissue and T cell distribution of precursor and mature IL-16. F Immunol 1998;161: tion of prect

14 Rumsaeng V, Cruikshank W, Foster B, et al. Human mast cells produce the CD4+ $\mathrm{T}$ lymphocyte chemoattractan factor IL16. F Immunol 1997;159:2904-10.
15 Lim K, Wan H, Bozza P, et al. Human eosinophils elaborate the lymphocyte chemoattractants IL-16 (lymphocyte chemoattractant factor) and RANTES. F Immunol 1996; 156:2566-70.

16 Laberge S, Ghaffar O, Boguniewicz M, et al. Association of increased CD4+ T-cell infiltration with increased IL-16 gene expression in atopic dermatitis. $\mathcal{F}$ Allergy Clin Immunol 1998;102:645-50.

17 Laberge S, Pinsonneault S, Ernst P, et al. Phenotype of IL-16-producing cells in bronchial mucosa: Evidence for the human eosinophil and mast cell as sources of IL-16 in asthma. Int Arch Allergy Immunol 1999;119:120-5.

18 Schluesener H, Seid K, Kretschmar J, et al. Leukocyte chemotactic factor, a natural ligand to CD4, is expressed by lymphocytes and microglial cells of the MS plaque. $\mathcal{F}$ Neurosci 1996;44:606-11.

19 Breitschopf H, Suchanek G, Gould R, et al. H. In situ hybridization with digoxigenin-labeled riboprobes: sensitive and reliable detection method applied to myelinating rat brain. Acta Neuropathol 1992;84:581-7.

20 Radzun H, Hansmann M, Heidebrecht H, et al. Detection of a monocyte/macrophage differentiation antigen in of a monocyte/macrophage differentiation antigen in routinely processed paraffin-embedded tissue by mon
clonal antibody Ki-M1P. Lab Invest 1991;65:306-16.

21 Parwaresch M, Radzun H, Hansmann M, et al. Monoclonal antibody Ki-M4 specifically recognizes human dendritic reticulum cells (follicular dendritic cells) and their possible precusors in blood. Blood 1983;62:585-90.

22 Konoff M, Strober W, Fiochi C, et al. CD4 positive Leu-8 negative helper-inducer T-cells predominate in the human intestinal lamina propria. F Immunol 1988;14:3029-36.

23 Kaser A, Dunzendorfer S, Offner F, et al. A role for IL-16 in the cross-talk between dendritic cells and T cells. F Immunol 1999;163:3232-8.

24 Laberge S, Cruikshank W, Kornfeld H, et al. Histamineinduced secretion of lymphocyte chemoattraction factor from CD8+ T-cells is independent of transcription and translation: Evidence for constitutive protein synthesis and storage. F Immunol 1995;155:2902-10.

25 Laberge S, Ernst P, Ghaffar G, et al. Increased expression of interleukin-16 in bronchial mucosa of subjects with atopic asthma. Am F Respir Cell Mol Biol 1997;17:193-202.

26 Mekori Y, Metcalfe D. Mast cell-T cell interactions. F Allergy Clin Immunol 1999;104:517-23.

27 Keates AC, Castagliuolo I, Cruickshank WW, et al. Interleukin 16 is up-regulated in Crohn's disease and participates in TNBS colitis in mice. Gastroenterology 2000; 119:972-82. 